\title{
AN ASSESSMENT OF ICT SUPPORT FOR STUDENTS LIVING WITH DISABILITIES AT THE UNIVERSITY OF NAMIBIA
}

\author{
Mathew Haitota ${ }^{1}$, Chirimbana Moses $^{2}$ and Haimbangu Malakia ${ }^{3}$ \\ ${ }^{1}$ Mathew Haitota Students Support Services University of Namibia (Main Campus) \\ ${ }^{2}$ School of Public Health, Department of Computer Science and the Science Foundation \\ program, University of Namibia (Oshakati Campus) \\ ${ }^{3}$ Ministry of Education, Arts and Culture (Omusati Directorate of Education)
}

\begin{abstract}
The purpose of the study was to assess the ICT support for the students living with disabilities at The University of Namibia. A qualitative methodology was used through the use of an in-depth face to face in interview which was administered to 12 participants who were lectures and disabled students from the University of Namibia disability Unity. The participants in the study were selected through the use of the purposeful strategy. The study findings unveiled that PCs cell phones and internet, software programmes, projectors and white boards, classroom televisions and radios downloaded app videos and braille's and hearing aids are some of the ICT equipment available for the students at living with disabilities at the University of Namibia. The study also established that lack of training in administrators, lecturers and disabled student who are in the disability unity of the University of Namibia in ICT equipment usage, lack of technical support from the University, lack of ICT resources, lectures low content knowledge and limited computer knowledge of the lectures for students living with disabilities are some of the challenges faced by students living with disabilities at the University of Namibia. The study also found out that there is need for management collaboration and support ICT resources for students living with disabilities. The study also revealed that the provision of incentives to the lecturers teaching students with disabilities will improve the lectures utilisation of ICT gadgets during the teaching of students living with disabilities at the University of Namibia. In addition, the study also recommended that monitoring and evaluation of the ICT support for the students living with disability need to be strengthened at the University of Namibia. Furthermore, the study also recommended that there should be collaboration between the various educational stakeholders in the provision of ICT support to students living with disabilities at the University of Namibia.
\end{abstract}

\section{KEYWORDS}

Disability, Support, ICT

\section{INTRODUCTION}

A disability is any condition which makes it more difficult for a person to do certain activities or interact with the world around them (Hines, 2019). These conditions, or impairments, may be cognitive, developmental, intellectual, mental, physical, sensory, or a combination of multiple factors. A physical disability is a limitation on a person's physical functioning, mobility, dexterity or stamina (Ngololo, 2010). Other physical disabilities include impairments which limit other facets of daily living, such as respiratory disorders, blindness, epilepsy and sleep disorders. 
International Journal on Integrating Technology in Education (IJITE), Vol.10, No.4, December 2021

The Commonwealth Disability Discrimination Act (DDA, 1992) stated that such an act of discrimination, is unlawful (Kinyanjui, Mwasa, \& Mbutu, 2014). According to Barnett, Kenhoo, Menarch, \& Washington (2008) higher education must address several challenges to align their educational practices with the principles of inclusive education. Inclusive education means that everyone should be included in society on an equal basis academically, socially and culturally. This implies that learners with barriers to learning are provided with education in age-appropriate regular classes in local schools according to their special educational needs (Zimba \& Beau, 2005). According to the Norwegian Directorate for Education and Training (2008: 3),

'inclusion is both a process and a goal, where the educational institution should accommodate the individual's aptitudes and needs in the best possible manner. This requires diversity and adaptation in an educational program to enable each individual to participate more and receive more benefits from being an active member of a community.'

In the Namibian context the people living with disabilities also form another group of marginalized groups who have been given special attention by the republic of Namibia. These people who fall under this group have either physical, disabilities, mental or the albinos. Such people in the Namibian context receive special treatment from the government have a range of disabilities receive grants from the government for them to sustain themselves. The University of Namibia gives special entry requirement for such people for them to receive education and other benefits (University of Namibia (UNAM), 2014).

The University of Namibia has a disability unit that caters for the needs of disabled students and they receive first preferences in terms of opportunities. The government has established the Ministry of disability affairs which runs in the office of the Vice President. This Ministry sees to it that the needs for people with disabilities are fairly met and are addressed. Depending on the nature of the disability of it does not require special skill, the people with disabilities always have lower entry qualifications in training institutions in all Namibian institutions (Shifonono, 2013).The Namibian government through the ministry of disability affairs has the requirements that all institutions in Namibia should have a path for a wheel chair so that such marginalized people can be mainstreamed in the education system without being segregated. This means these students with disability have to be provided ICT gadgets which will allow them to be able to keep in pace with the incessantly changing information age. However, the provision of such ICT gadgets by UNAM seems to be a challenge due as a result of various factors which include among others, lack of finance, and inability to utilise and service the available gadgets. Therefore, this study made an assessment of the ICT gadgets which are meant to be used by students with disabilities at UNAM.

A student's environment has a huge impact on the experience and extent of disability". Barriers, to participate and inclusion, are formed due to inaccessible environments (WHO, 2011). In this regard research showed that not all students have equal access to information technology (Wu et al., 2014; Mavrou, Meletiou-Mavrotheris, Halili, \& Sulaiman, 2018). Students living with disabilities are less likely to enrol for post-secondary education due to their disability and support at such institutions (Omwancha, 2012). There are is limited literature related to ICT and disability in UNAM. The only study that has focused on the implementation of the ICT policy in the context of the Faculty of Education at the University of Namibia (Isaacs, Kazembe \& Kazondovi, 2018). The study by Bingimlas (2019) was concerned with teacher educators and did not evaluate the effectiveness of the policy from the students' perspective. This study therefore investigated the technology support among students living with disabilities at the University of Namibia. 


\section{LiterATURE REVIEW}

\subsection{Theoretical Framework}

The aim of the study was to assess the ICT support for students living with disabilities. The Connectivism Theory (CT) by George Siemens was used to lay the theoretical lens of the current study. In line with this theory, George Siemens envisages that connectivism forms the starting point for learning occurs when knowledge is actuated through the process of a learner connecting to and feeding information into a learning community (Omwancha, 2012). In line with the connectivism theory, knowledge is distributed across an information network and can be stored in a variety of digital formats. Connectivism is a theory of learning in a digital age that emphasizes the role of social and cultural context in how and where learning occurs. Learning does not simply happen within an individual, but within and across the networks. Knowledge in connectivism is a chaotic, shifting phenomenon as nodes come and go and as information flows across networks that themselves are inter-connected with myriad other networks (Riesen, McDonnell, Johnson, Polychronis, \& Jameson, 2003).

\subsection{Specific ICT support provided for students with disability}

Information and Communication Technologies (ICT), when accessible and available, can serve as critical enablers that allow persons with disabilities to realize full and effective opportunities to participate, on the basis of equality, in all aspects of society and development (Mingaine, 2013). ICTs can help persons with disabilities to have greater access to knowledge and independent living. However, there are a few principles that should be taken into consideration while introducing ICTs (Bingimlas, 2009). Whether one is considering the respective needs of rich and poor, rural and urban, those with access to the internet and those without (the digital devide), ICT has the power to bring people together. Wi-Fi access is essential, as is access to a stable electrical supply. One side of the match is the description of the learning resource (Zimba \& Beau, 2005). An important addition to the metadata standards is Accessibility Metadata. Accessibility Metadata elements provide information about the resource such as the senses needed to process the resource, the ability of content to transform in ways necessary for accessibility and the availability of equivalent resources (Catana, 2015). Equivalent or alternative resources replace or supplement primary resources to address an accessibility issue that a learner may have with the primary resource. Through accessibility metadata, resources that are accessible or can be made accessible are easily identified and utilized by educators, learners or the learning management system they employ (Hines, 2019).

\subsection{ICT resources and support for students living with disabilities}

Assistive or enabling technology includes devices, tools, hardware, or software, which enable, partially, people with disabilities to use the computer (Shifonono, 2013). It presents an alternative way to access the content on screen, command the computer or process data. Specific adjustment software or devices for manipulating the computer include (Riesen, McDonnell, Johnson, Polychronis, \& Jameson, 2003). In most learning environments for disabled individuals reading is done using the screen reading software. This software speaks displayed text and allows simulating mouse actions with the keyboard and is mostly used by those individuals who have visual impairment.

There is also a screen magnification software which is used for enlarging the content of the screen according to (Zimba \& Beau, 2005). Some students with visual impairment problems make use of the braille display for displaying Braille characters, while other students with 
disabilities make use of alternate input devices (e. g. Screen keyboard) and special keyboard (to make data entry easier). Other students' visual impairment makes use keyboard enhancements and accelerators (like StickKeys, Mousekeys, repeatKeys, SlowKeys, BounceKeys, or ToggleKeys), mnemonics and shortcut keys to enhance their learning (Kenny \& Qiang, 2003). In other learning environments for students with disabilities there are some alternative pointing devices (e. g. Foot operated mice, head mounted pointing device, or eye tracking systems) which students make use of if they are visually impaired disabilities (Mingaine, 2013; Ministry of Education Sports and Culture (MoESC), 2010). These aiding technologies can be either devices or equipment (hardware) e.g. Braille, or software applications e.g. screen reading software. However, these technologies do not seem sufficient for providing full support to people with disabilities (Zimba \& Beau, 2005). Web content providers should also participate in the inclusion process by making arrangements that allow particularities of people with disabilities to be taken into account when creating web content.

\subsection{ICT related challenges faced by students living with disabilities}

Some of these systems are limited in a particular environment so the posterior applications cannot profit from the valuable experiences gained through local use and consequently cannot be easily identified and adopted by larger communities of educational practitioners and training organizations (Ngololo, 2015). Many of them are typically based on accessible learning content that is designed and only recognizes the specific accessibility requirements of a particular user group (Hines, 2019). The e-learning environment may contain some non-accessible tools that prevent people with disabilities access to the content even though this is in an accessible format. Some systems may provide content during the learning process that does not meet the specific needs of each type of disability. Some systems use accessible learning resource designed to be accessible to everyone, but not optimal to every user. Most systems lack the possibilities of personalization since they give the same contents to all students (Shifonono, 2013). Remedy to the lack of environments, taking into account the design of accessible e-Learning applications. Lead the learner in specifying his needs and preferences regarding the control as well as the presentation of the learning content he wishes to exploit in the e-Learning environment.

\subsection{Strategies to improve the Information and Communication Technology to support students living with disabilities}

Remarkably, solutions exist and have in fact been implemented around the world addressing most disabilities since 2005 (Barnett, Kenhoo, Menarch, \& Washington, 2008). This section briefly explains what ICT accessibility and assistive technologies are and the importance of specific standards which have been developed for different technologies, services and content. In general, ICT products, content and services can be made accessible to most users with disabilities if there is provision for alternative modes of interaction; outputs in multiple possible formats; customization of configuration and settings; and compatibility with assistive technology (Omwancha, 2012). Accessible interfaces are characterized by three basic principles according to (Mingaine, 2013:167). The user must be able to: (1) perceive it (awareness and access to contents displayed) (2) understand it (know what it means and how to interact with it); (3) operate it (be able to interact with it in a certain way to produce intended/desired results). To design accessible ICTs, it is essential to consider the user perspective in all aspects - from the way equipment is designed to its use and where it is located or placed.

Being conscious of the constraints witnessed by people with disabilities in everyday life especially with web based applications, the W3C carried out a key solution promoting people with disabilities in accessing, using and interacting with the web through the Web Accessibility Initiative (WAI) (Zimba \& Beau, 2005). The WAI develops strategies, guidelines, and resources 
to make the web accessible to people with disabilities (W3C Web Accessibility Initiative, 2013). The WAI targets, among others, web content through Web Content Accessibility Guidelines (WCAG) (Web Content Accessibility Guidelines, 2013), authoring tools through Authoring Tools Accessibility Guidelines (ATAG) (Authoring Tools Accessibility Guidelines, 2013) and user agent through User Agent Accessibility Guidelines (UAAG) (User Agent Accessibility Guidelines, 2013). In the WAI model, the WCAG is complemented by accessibility guidelines for browsing and access technologies (UAAG) and for tools to support creation of Web content (ATAG) (Sloan et al., 2006:16). These guidelines are mainly based on the following four criteria: (1) Perceivable - information and user interface components must be presentable to users in ways they can perceive (2) Operable - user interface components and navigation must be operable (3) Understandable - information and the operation of user interface must be understandable (4) Robust - content must be robust enough that it can be interpreted reliably by a wide variety of user agents, including assistive technologies (Hines, 2019). The WAI was widely deployed in various web application areas aiming to include the left-out user groups. In fact, this inclusion became an acquired right for the people suffering from disabilities in different countries. Since education is one of the major concerns of ICT, applying WAI in this domain is very promising (Shikongo, 2016).

\section{Methodology}

This study used of Phenomenological qualitative research strategy and a descriptive exploratory design to investigate the technology support among students living with disabilities at the University of Namibia. Phenomenological approach, for instance, attempts to uncover, interpret and understand the participants' experience (Antwi \& Hamza, 2015). Similarly, Babbie \& Mouton (2012) may focus on the participants' experience rather than any other imperative issues in the context. The current study used the purposeful/judgemental sampling strategy to select twelve (12) participants from the disability unit and this selection included the students with disability and the lecturers and adminitrators. This strategy was appropriate in that the researcher selected those staff members he knows would provide him with the information that she needed (Boyle and Boffetta, 2013). The data for the study was collected through the use of an in-depth face to face interview with the students and staff from the disability Unit of the University of Namibia (Chirimbana, 2016).

\subsection{Theme 1: ICT Resources and Support that are Available to Students Living With Disabilities at the University of Namibia}

Those countries, which are highly developed, are making use of advanced electronic media and gadgets, which are given to the learners, while those countries that are still developing especially in the African continent and the Latin American communities are utilizing those gadgets, which they can also afford to purchase. These gadgets range from television, laptops, projectors, downloaded applications, you tube videos among others and they depend on whether the particular teacher is able to make use or operate such gadgets (Shikongo, 2016). These participants in the study indicated diverse varieties of ICT gadgets, which they are making use of in their teaching of students with disabilities in schools. On this aspect, this is what the study participants 9 had this to say, "I am making use of videos and television sets and video recorders to teach students with disabilities in my modules.", This was echoed by participants 10 who also stated that, "I make use of radios and you tube videos to teach students with disabilities since these are effective in allowing the learners to see and listen."

These findings concur with the earlier findings by Ahmad, Ludin, Ekhsan, Rosmani, \& Ismail (2012) who argues that the use of ICT gudgets in the teaching of students with disabilities makes 
International Journal on Integrating Technology in Education (IJITE), Vol.10, No.4, December 2021

the teaching of english not only interesting but also understandable. On this note, Henbest \& Apel (2017) sytated that the use of ICT can be used to make students with disabilities their content.

\subsubsection{Sub-theme 1.1: PC, Cell phones and internet}

Computers, laptops, notebooks, tablets, and smart phones have been adapted for people with visual impairments through special programs and equipment called Assistive Technology (AT) which is any technological device or service that helps people overcome the challenges of their disabilities (Badugela, 2012). AT includes everything from smart glasses for the blind to voice recognition programs that type for you and follow commands as you speak. Assistive Technology allows people who are blind or visually impaired to utilize computers in a similar way as sighted individuals (Catana, 2015). Desktops offer larger storage capabilities and faster operating systems than portable computers. They often come with accessibility programs such as screen reader software and the ability to enlarge fonts and contrast colours and backgrounds (to aid colourblind). Participants in the study indicated that the University of Namibia supports the students with disabilities through the use of the various IT gadgets depending on the type of disability which a particular student has. The citations below from the various participants 6 in the study had this to say, "The University supports us using personal computers and other electronic devices which we are making use of to make our learning easy". On this issue, participant 4 had this to say," The university provide us with internet facilities through the use of the dongles and data banks which are billed on our students 'accounts."

\subsubsection{Sub-theme 1.2 Programs to support students with disability}

Participants in the study indicated that they have various software's which they use in to enhance and facilitate their learning. On this issue, this is what the participants in the study had to say: Participant indicated that, "I make use of FM systems wireless devices that directly transmit sounds to a hearing aid to communicate clearly with students who have hearing loss, even in a noisy classroom." Participant 9 indicated that he "I make use of the Flip grid with closed-caption features, as well as videoconferencing tools such as Microsoft Teams, which comes with live captioning and subtitles." Participant 12 in this study had this to say, "I make use of the Microsoft's Immersive Reader, which was specifically designed to support students with dyslexia and dysgraphia. With the Immersive Reader, students can have text read out loud and broken into syllables even in other languages. Microsoft's Tell Me feature allows students to access commands on Office 365 applications without having to remember them".

\subsubsection{Sub-theme 1.3 Projectors and white boards}

The use of white boards has the advantage that the review of lessons becomes more convenient and it keeps it easier for the teacher to structure lessons, makes the teaching and learning more fun (Mingaine, 2013). It also makes the learning process fun, and increase the levels of engagement of the teachers and the students in the learning environment. On this issue, the participant 1 in the study had this to say, "We have installed white boards in our classrooms which teachers are using when teaching learners with disabilities. "Participant 4 had this to say, "Projectors are there and they have been installed but they only benefit those who can see but those who cannot see will not benefit from them."

\subsubsection{Sub-theme 1.4 Classroom television, radios}

Television can be used as an effective teaching tool to help build literacy skills, address current social issues and energize classroom dynamics (University of Namibia (UNAM), 2014). The participants in the study indicated that they have access to televisions and radios being used to 
International Journal on Integrating Technology in Education (IJITE), Vol.10, No.4, December 2021

teach the students with disabilities. On this issue, this is what participant 10 had to say, "Imake use of radios and televisions and they make the teaching easier and interesting for the students." On the same note, participant 12 said that, "I make use of radios and make the teaching students with disabilities this enhances greater understanding to these students. At our University has, televisions which are meant specifically for disabled students using the television, learning is made more meaningful and exciting to the students."

\subsubsection{Sub-theme 1.5 Download app videos}

The use of video applications in the teaching of students is one of the methods that has proved to be effective in teaching students with disabilities (Mingaine, 2013). Videos have the advantage that they create a more engaging sensory experience than using print materials alone (Quest, 2014). In addition, videos also help to provide a go-to resource that can be watched from anywhere with an internet connection. Videos also increase knowledge retention, since they can be stopped and replayed as many times as needed (Zimba \& Beau, 2005). However, even though they have notable advantages, they also have the disadvantage that if they are not captioned with subtitles they can be difficult for the hearing impaired to access. In addition, the use of videos has the challenge that if the teachers have no knowledge or experience in using videos other than for recording lectures videos will not be effective. On the use of video use, this is what participant 10 had to say, "Make use of application videos and that make my teaching of students with disabilities more enriching and rewarding to the learners." On this issue, this is what participant 8 had to say, "I normally use my cell phone to download some application videos and I use these to teach my students how to develop order understanding."

\subsubsection{Sub-theme 1.6 Provision of Brails and hearing aids}

A hearing aid is a small electronic device that you wear in or behind your ear. It makes some sounds louder so that a person with hearing loss can listen, communicate, and participate more fully in daily activities. A hearing aid can help people hear more in both quiet and noisy situations (Salomo, 2018). Along with lip-reading and interpreters, students may use technology like hearing aids, assistive listening devices, and captioning or transcription. With or without this technology, teachers can also make a variety of accommodations to help these students learn. Participant 1 in the study indicated that," The university assist the students with hearing aids and braille's for them to be able to learn. "Participant 5 indicated that, "I received my braille from the university and its helping me to do my work because I have visual impairment problem." Participant 11 had this to say, "I allow enough time for the student to get the information from the interpreter before calling on someone. I give them enough time to work on their braille's."

\subsection{Theme 2: ICT Related Challenges are Faced by Students Living with Disabilities at the University of Namibia}

The use of ICT in the teaching of students with disabilities faces several challenges especially in the implementation processes (Ariandika \& Kartikawati, 2018). These challenges vary from student to student, lecturer to lecturer and from individual to individuals. The challenges are possible impediments that inhibit successful implementation of the teaching of students' disabilities at the University of Namibia. These challenges range from institutional to personal and they are all responsible for the failure in the implementation plan for ICT integration in the teaching of students with disabilities. The participant 1 in the study indicated that they face numerous challenges in their use of ICT in the teaching of students with disabilities. On this, this is what he had to say," "I don't have the relevant ICT skills to teach phonemes in my classrooms and this makes me to rather resort to other non-technological methods." Another participant in the study was participant 12 who also said that, "We don't have the relevant ICT resources to use 
International Journal on Integrating Technology in Education (IJITE), Vol.10, No.4, December 2021

in the teaching of students with disabilities using ICT." Participant 10 also indicated that, "I have low content ICT knowledge and this makes me not to even try using ICT in teaching students with disabilities in my classes.".

\subsubsection{Sub-theme 2.1 Lack of training in ICT equipment usage}

Research findings obtained from this study indicated that the majority of teachers who are utilising ICT devices and software's for teaching students with disabilities are swamped with lack of effective training. Some of respondents stated that the improper use of ICT devices in in the teaching of students with disabilities at the University of Namibia is aggravated and emanated from the incompetence of teachers and as a result of this, most of the lecturers are not able to efficiently deliver their lessons using ICT teaching devices (Bingimlas, 2019). This in turn has a negative repercussion on disabled students' understanding of the various aspects. Participant 5 interviewed under unstructured interview in this study stated that, "the moment we were trained at colleges and universities we were never taught anything do with the use of ICT devices in teaching students with disabilities, that's why we are confronting various challenges in the use of ICT devises". This was well supported by participant 12 in the study who indicated that, "Given this situation, lack of technical know-how among lecturers in using the devises rendered the majority of the students in the passing of various subjects in their different programmes."

\subsubsection{Sub-theme 2.2 Lack of technical support from the University management}

Lack of technical support or knowledge is the support rendered to an organisational employees by the management (Agrawal, et al., 2010). With the lack of funding, it also means that there is very little technological support and that often leaves them overworked and unable to meet the needs of the teachers (Omwancha, 2012). Technical support (often shortened to tech support) refers to services that entities provide to users of technology products or services. Technical support may be delivered by phone, e-mail, live support software, live chat or website, or other tools where users can log an incident. A institutions can increase service provisions if they have an exceptional technical support team (Catana, 2015). This is why some institutions even get help from tech support outsourcing companies. A good technical support is when a company provides user-friendly assistance to its consumers. Participant 8 in the in the study indicated lack of technical support as one of the challenges by students with disabilities at the university of Namibia. On this issue, this is what participant 8 had to say," We do not have adequate technical support from the university. " On this issuer, this is what participant 7 had to say," The university doesn't have money to provide technical support to the students with disabilities especially this error of COVID 19".

\subsubsection{Sub-theme 2.3 Lack of ICT resources e.g. smartphones, applications and projectors}

Information and Communication Technology or "ICT," includes products that store, process, transmit, convert, duplicate, or receive electronic information (Salomo, 2018). Electronic textbooks, instructional software, email, chat, and distance learning programs are also examples of ICT resources. Without these resources the use of ICT becomes inevitable in any institution. The main problems are high cost of getting, installing, operating, maintaining, and replacing ICT systems, use of unlicensed software, outdated hardware and software systems, lack of technical support for maintenance of systems (Mingaine, 2013).

Participant 10 in the study indicated that lack of resources inhibit them from using ICT I the teaching of disabled students. On this issue this is what the study participants had to say," We don't have enough braille's, hearing aids and other electronic software's that are needed by the disabled students." This problem is making it hard the general, several studies have identified a 
International Journal on Integrating Technology in Education (IJITE), Vol.10, No.4, December 2021

range of the following or similar factors as widespread barriers. Participant 5 in the study had this to say," We have a shortage of computers, lack of quality software, lack of time, technical problems, teachers' attitudes towards computers, poor funding, lack of teacher confidence, resistance to change, poor administrative, confidence, lack of competence, and lack of access to resources."

\subsubsection{Sub-theme 2.4 Lectures low content knowledge}

Participant 10 in the study indicated that, "some of the teachers are not really specialists in teaching disabled students and for this reason they lack the most needed content knowledge to teach their various subjects." This was well supported by participant 1 who said that, "Our teachers lack pedagogical knowledge to teach the students with and pedagogical knowledge, to make content specific connections between solutions; ask a particular question during a discussion to push the content of the lesson; organize discussions to facilitate progress along a content trajectory; and. use representations to convey content specific meaning."

\subsubsection{Sub-theme 2.5 Limited computer knowledge by lectures and students}

For teachers or lecturers to make use of ICT innovations in the teaching they need to have the knowledge of such inventions (Ariandika \& Kartikawati, 2018). If the teacher is not having sufficient knowledge in in using the ICT tool the success in the use of ICT will remain a dream (Shifonono, 2013). The knowledge to use ICT develops as one is exposed more and more to the ICT tools. This knowledge can be developed through in-service training of the teachers in using these inventions. Findings of the study unearthed that the absence of computer know- how pertaining the use of ICT in schools inhibit teacher's self-confidence in the use of ICT devices and software (Riesen, McDonnell, Johnson, Polychronis, \& Jameson, 2003). Participant 10 in the study indicated that, "most of the lecturers in the University do not possesses the right computer knowledge that can make them effective in the reaching of students with disability using ICT in the use of ICT and this exacerbated the straining of teachers from the use of technological devices in teaching of disabled students using ICT".These findings are supporting the findings of supported by participant 4 who stated that, "some school teachers are not confidence in the utilization of ICT devices in a classroom." On this issue, Participant 11 highlighted that," the chief cause of this is lack of self-confidence which prevents teachers from employing ICT tools when they are in front of the learners in classrooms". Participant 9 in the study had this to say, "It is difficult for us to useICT devices and software due to the fact that we do not possess the pedagogical implementation of it. Additionally, lack of self-confidence makes us incompetent to apply ICT devices in class when delivering a lesson." These findings are in line with the findings of Walker, Bet al. (2013) who indicated that teachers are not confident and competent in delivering a lesson using ICT devices especially in the teaching of disabled students and this in turn affects the flow of information from the teacher to the learners.

\subsubsection{Sub-theme 2.6 Poor implementation of ICT tools and devices}

Poor implementation of curriculum is one of the challenges faced in teaching and learning. The teachers and lecturers are the ones who are at the forefront of implementing curriculum in schools and colleges. If the teacher has no understanding of the curriculum they are implementing this means the students will not master the curriculum (Mingaine, 2013). It became apparent that there are major curriculum challenges facing teachers in schools and teachers in managing the curriculum implementation in their schools. Curriculum implementation refers to how teachers deliver instruction and assessment through the use of specified resources provided in a curriculum (Ngololo, 2010). Participant 5 in the study indicated that, "We face the challenge of implementing the curriculum because some of us are not specialists in ICT curriculum 
International Journal on Integrating Technology in Education (IJITE), Vol.10, No.4, December 2021

implementation especially for students with disabilities. "On this matter, this is what participant 12 had to say, "We really need guidance, support and assistance in the implementation of ICT in the teaching of disabled students."

\subsection{THEME 3: Strategies Can Be Used to Improve the Information and Communication Technology Support among Students Living With Disabilities at the University of Namibia}

The participants in the study indicated many strategies that could be effective in improving teachers' utilization of ICT in the teaching of students with disabilities and these strategies differ from individual to individual. Of importance, the study participants highlighted the following strategies: Participant 12 had this to say, "There is need for support from the ministry of higher education in ICT usage in the teaching and learning of students living with disabilities." On the same issue, Participant 4 had this to say, "The Ministry of Education work together to help us with the technical knowhow in ICT usage in the teaching of various subjects" This ongoing debate was supported by participant 1 who indicated that "supporting lecturers through inservice training, improving the monitoring and evaluation of ICT in schools would improve the teachers' utilization of ICT in the teaching of students with disabilities." Participant 10 also stated that "strengthening the existing ICT policies for ICT in the teaching of students with disabilities would mitigate on the challenges students and lecturers are facing in their desire to utilize this teaching initiative. "Participant 5 also reiterated that "rewarding the teachers who take a lead in advancing their ICT skills in schools would help to advance the teachers utilization of ICT in the teaching various subjects."

\subsubsection{Sub-theme 3.1 Giving rewards to all lecturers who accept going for ICT support training}

Effective employee rewards can reduce stress, improve sleep and even increase metabolism. Employee reward and recognition has been proven to improve organisational values, enhance team efforts, increase customer satisfaction and motivate certain behaviours amongst members of staff (Flamholtz, 2002). Participant 7 in the study indicated that, "If lecturers who accepts to go for ICT support training are rewarded this would mean the majority of the lecturers teaching students with disabilities will become more effective in their work." On the same note, Participant 2 said that, "There is need to reward those lecturers who accepts to be trained on ICT usage so that the reward will act as a motivation to the students' success."

\subsubsection{Sub-theme 3.2 In-service-training and computer usage for lecturers}

In-service training has proved to be an effective way to equip and enhance employee skills. This iniative has been found to be helpful in mitigating on on low staff competencies (Lin et al., 2011). Inservice training helped to improve on job satisfaction and morale among employees and improve on employee motivation, increased efficiencies in processes, resulting in financial gain, increased capacity to adopt new technologies and methods. In the current study particpant 12 irretarated that,"the lecturers need to undergo insavice training on ICT usage in the teaching of students with disabilities." On that issue, participant 1 had this to say, "Our lecturers need to undergo some inservice training for them to be able to use modern ICT equipment and gudgets since most of theme were trained before these innovations were founded." 


\subsubsection{Sub-theme 3.3 Employees institutional support}

Institutions need to support their employees so that as they work to achieve the institutions common goals and objectives and missions (Catana, 2015). Ehri and Nunes (2002) indicated that institutional support promotes self-efficacy and innovative behaviour that help develop positive employee perceptions, administrative data processing; space management; employee personnel and records. Institutional support is most easily obtained by building personal relationships with administrators (Shifonono, 2013). The question of financial and resource support was only in the interview guide for the support teachers (Mingaine, 2013). On this issue this is what the participant 10 had this to say, "We need the support of our university especially with ICT gadgets for students with disabilities." Participant 2 had this to say, "If the university could support the unit with ICT equipment this will go a long way in helping the students who are living with disabilities."

\subsubsection{Sub-theme 3.4 Buy ICT programs that can support the student's disabilities}

The provision of ICT programmes for the students living with disabilities is a way of supporting this group of people (Shikongo, 2016). If these students living with disabilities are well supported they will perform well in their education and they will become light bearers and become selfsustainable rather than relying on government for things. These gadgets can include computers, computer programmes, braille machines, and hearing aids for the partially deaf, and other software's which are needed to aid on the communication of the students living with disabilities (Ngololo, 2010). Participant 8 in the study had this to say," There is need for the UNAM to buy some ICT equipment that are needed by the by the students with disabilities." On this matter participant 2 had this to say, "We need the university to by us ICT equipment to support the disabled students." These findings uphold the findings of Ariandika and KartikawatI (2018) who stated that every organisation need to have an ICT department that regulates and provide ICT quipment for all its employees including those who are disabled.

\subsubsection{Sub-theme 3.5 Improving monitoring and evaluation on ICT policy implementation}

Lecturer's performance evaluation criteria should be clearly spelled out and communicated to all employees. Lecturer's should be evaluated impartially considering the performance standard set. Therefore, to avoid the situation of conflicts to arise in organizations related to performance evaluation, the standards set by management should be specific, measurable, achievable and realistic and should have time limit (SMART) (Nicanor, 2015). In addition, the employees should be reviewed and get the progress report on their performance. This will make lecturers to know their strengths and weaknesses. On this issue, this is what participant 9 had to say," UNAM need to have a proper monitoring and evaluation criteria so that the management can evaluate the lecturers performance. "This was well supported by participant 2 who said that, "If UNAM can improve on its monitoring and evaluation strategies, it has the potential to improve its productive capacity especially in the performance of the students living with disabilities." The findings above concur with the findings of Zimba and Beau (2005) who stated that organisational success lies in the availability of proper monitoring and evaluation structures which can be used by management to assess their own productivity.

Monitoring and evaluation of any system are an important aspect that needs to be undertaken in order to see whether or not the system is progressing well or is not doing well. Monitoring and evaluation allows the stakeholders to assess the effectiveness of the system and challenges that need to be overcome in order to get the best results out of the system (Riesen, McDonnell, Johnson, Polychronis, \& Jameson, 2003). However, the participants in the study found out that there is poor monitoring and evaluation of the proceedings in schools. In this regard, this is what 
International Journal on Integrating Technology in Education (IJITE), Vol.10, No.4, December 2021

the participant 7 had to say: "The monitoring process is very less. "This was supported by participant 12 who said that, "There is poor monitoring and evaluation of our successes and failures in the teaching profession." Participant 1 had this to say on the matter, "The Disability Unit needs to go around other similar departments in the country and see how teachers are implementing their ICT policy. We need motivation and assistance where we are doing it wrong." (Participant 1)

\subsubsection{Sub-theme 3.6: Collaborating with private entities to support the learners with disabilities}

Collaboration is a working practice whereby individuals work together for a common purpose to achieve business benefit (De Beer, 2006). Collaboration enables individuals to work together to achieve a defined and common business purpose and it is about working together for common goals. As the collaborative relationship is forming it's important that all parties understand and agree on the shared goals of the project (Mingaine, 2013). Efficiency is an essential part of a team and an important aspect of the workplace. Workplace collaboration will keep everyone safe from extra load of work as the work gets distributed evenly. Participant 11 in the study had this to say about collaboration," There is need for our lectures, and the administrators to collaborate together in solving and attending to the problems we are facing ad students living with disabilities in the University. "This was well supported by participant 6 when he said that," The entire disability unit need to collaborate with other departments and with the university management in rendering support to the students living with disabilities."

\subsubsection{Sub-theme 3.7: Availing of resources for ICT}

Once a person gets employed, he/she automatically becomes a human resource of that organization (Ngololo, 2010). The precautions of social, environment, political and economic factors which have forced many organisations to retrench their workers, makes the organisation to produce far below capital utilization (Becker, 2009). Human resources of any organisation hold the key to its survival, profitability and sales growth which entails prosperity, future economic and social development. Every organisation needs three main resources to survive. The three main resources needed include -Financial resources, Physical resource which include material and Human (Mingaine, 2013). Any organisation needs money to pay its staff and buy essential materials or equipment for operation (Shifonono, 2013). There is no organisation with no human resources that can remain productive in its business. Even though an organisation has got all the money and machine or material needed, it must still find capable people to put them into effective use. It is therefore logical to claim that human resources are the most important of the three essential resources of an organization (Nicanor, 2015). In this study the participants highlighted that if resource availability is enhanced; this will increase their productive capacity and get the company on toes again. Besides, the amount of capital invested in an organisation its success or failure depends on the quality of people who executive its programme (Omwancha, 2012). The following sentiments from participant 2 substantiate this theme, "We really need financial resources, so that the university can smoothly operate". This was seconded by participant 11 when he said, "The University doesn't have sufficient financial resources, and other material resources needed support the students living with disabilities".

\section{DisCuSSION OF THE FINDINGS}

These findings are supports and corroborate with the findings of Barnard and Campbell (2005) who indicated that the use of cell phones and PC and laptops can be very helpful especially in teaching learners with various disabilities and this can be helpful in the sense that the students will be downloading videos and making use of them in the class. Zimba and Beau (2005) 
indicated that the use of some downloadable fonts such as Open Dyslexic, can enhance readability and reading speed for students with dyslexia.

The findings corroborates with the findings of Zimba (2012) who indicated that whiteboards are simple touse and require no special skills and are reusable and can be erased quickly and reused for quick explanations and spontaneous work. Whiteboards are great for explaining math problems, reading texts, matching exercises, ranking activities, discussion activities and other unfolding processes. Chemwei, Leboo, and Koech (2014) highlighted that whiteboards are effective in numerous settings that require spontaneous, quick-feedback. On these findings, Bingimlas (2019) indicated that TVs have the advantage that it is a source of entertainment. With a wide array of channels to choose from, the television ensures that everyone is catered for. Better even than listening to an audiobook or reading one on an e-reader. It reduces stress, promotes comprehension and imagination, alleviates depression, helps you sleep and may contribute to preventing Alzheimer's. Reading is active; watching TV is passive (Hays, 2016).

On these findings, Colburn (2000) argues that the absence of ICT recommended technological training in teacher education programs or in service lecturer trainings is the chief obstruction which hinders the efficacy use of ICT devises and software in teaching students with disabilities. Based on these findings, it can be started that the most challenge to ICT integration is lack of skill. This aspect is an important component in ICT integration among the students with disabilities use the ICT gadget if he doesn't have the skill and the technical knowhow of how to use it. The Technology Acceptance Model (TAM) and the Theory of Reasoned Action indicated that one need to accept and acknowledge that the use of a technological innovation can improve their teaching and learning for them to be able to use such technology. On the note the theory of reasoned action stipulates that one need to perceive a technological innovation as being effective before they can accept its use in the teaching and learning.

On this matter, participant 1 who in this study said this, "poor technical service maintenance of ICT tool and software results in poor teaching of students with disabilities because of habitually technical faults of internet website connect and this forced to be not competent to conduct the lessons. Another participant in the study participant 5 also indicated that, "We do not have technical support that we need from the ICT technicians in the school and this makes it hard for us to utilize ICT in the teaching of students with disabilities." To concretize the aforementioned challenge, it is imperative to elucidate that ICT technical faults act as an obstruction, which inhibits the use of ICT tools and devices in efficacy delivery of lessons to students with disabilities at the University of Namibia.

These findings Curriculum implementation is an important aspect that enhances success of teaching and learning in schools (Akram \& Malik, 2010). If teachers have no knowledge of how to implement their ICT policies in their teaching, success in teaching will not take place in schools (Zimba \& Beau, 2005). The poor implementation of ICT tools and devices in schools stems from poor ICT policy understanding. Basing on this, it problematic for a teacher to attend and supervise all learners' problems and sometimes when the higher rank learners understood what is being taught, a teacher moved to another subject topic and the slower learners are left in darkness pertaining what was (Mingaine, 2013). These findings validate the findings of Omwancha (2012) who stated that poor implementation of ICT tools and devices stemmed from class organisation and from classes which focuses on integrating learners with different ranking in terms of capturing what had been taught in class. These findings further harmonise with the findings of Hodgson, Heather , Conridge, Gibbons, and Robinson (2018) who also disclosed that there is contradiction between policy implementation in relation to the use of ICT in to enhance the teaching and learning process. 
International Journal on Integrating Technology in Education (IJITE), Vol.10, No.4, December 2021

The above findings support and upholds the findings of Westhuizen (2014) who indicated that motivation and evaluation is an effective tool that can be used to check the progress towards meeting objectives. When monitoring is occurring regularly, schools will be more sincere and improved regarding the implementation of policies. This will help the implemnters of learning support to get support, they all need to effectively implement the learner support policy in schools.

Riesen, McDonnell, Johnson, Polychronis, \& Jameson (2003) supports these findings by saying that collaboration in organisations helps to solve problems and also brings people (and organizations) closer together, helps people learn from each other, It opens up new channels for communication, boosts morale across your organization. By working together, employees achieve something greater than if they are working alone. Collaboration not only equals a happier workforce, it represents an educated one (Masunda, 2013). These findings further collaborate with the findings of Foster and Kaplan (2011) who stated that organisations should maintain strong human resource for optimal performance. In order for organisation to survive, it must train and develop its human resources, for it is the human resources that hold the key to its survival, prosperity, future economic and social development. The success of any organisations is also by ensuring that the available human resources are motivated adequately (Omwancha, 2012). Therefore, it's the prime responsibility of the management to ensure that the available scarce resources are utilized properly for the benefit of the organisation and other stakeholders (Hines, 2019)

\subsection{Limitations of the Study}

All the participants in the study were administrators, lecturers and disabled student who are in the disability unity of the University of Namibia and were sampled using purposeful random sampling strategy. Since the participants were students and employees for the University of Namibia disability unit, time to undergo the in-depth face to face interview was not sufficient and the researcher had to arrange with all the participants when they are free during lunch hour or any other time.

\subsection{Recommendations to the University of Namibia and Ministry of Higher Education}

The University of Namibia disability Unit is the department responsible for the students living with disability at UNAM. Disabled students face numerous ICT related challenges in their academic endeavours:

- Therefore, the study recommends that lecturers be provided with in-service training in using the ICT training for students living with disabilities at UNAM.

- The university management should improve their provision of ICT equipment to students living with disabilities at the University of Namibia.

- The University of Namibia should collaborate with other stakeholders in order to outsource the ICT gadgets that can be used by students living with disabilities.

- There is need to continuously monitor and assess the implementation of the ICT policy to the students living with disability at UNAM. 
International Journal on Integrating Technology in Education (IJITE), Vol.10, No.4, December 2021

\subsection{Suggestions for further research}

This study was done at the University of Namibia Main Campus in the disability Unit. Therefore, studies need to be done in other University Campuses of the University of Namibia and other high institutions in Namibia so that the findings:

- Compare the findings so as to have a better understanding of the ICT support rendered to students living with disabilities within the University of Namibia.

- To compare these support measures and the challenges across other Universities in Namibia.

\section{CONClusion}

A qualitative approach was used to answer the research questions, thereby attaining the research goal and objectives of the study. The results of this study provided insight into the ICT support measures rendered to students living with disabilities at the University of Namibia. This last chapter of the study provided the reader with a summary and the conclusions of the preceding chapters, from the introduction, theoretical framework, literature review, applied methodology and the presentation of the research findings. A number of recommendations were made to the University of Namibia. In addition, the researcher made suggestions for future research. In conclusion, the study is expected to add new knowledge to a limited body of literature on the ICT support rendered to students living with disabilities in tertiary institutions.

\section{REFERENCES}

[1] Barnett, B., Kenhoo, M., Menarch, U., \& Washington, E. (2008). "creating a sustenable teacher resilience among urban teachr residence:A new way to recuit,Prepare and retain effective teachers in high needs Districts". Washington,D.C: Aspen Institute.

[2] Bingimlas, K. (2019). Barriers to the successful integration of ICT in teaching and learning environments: A review of literature. Eurasia Journal of Mathematics, Science \& Technology Education, 5(3), 235-245.

[3] Catana, L. (2015). Conflicts between teachers: causes and effects. Public full text, 3(3) 24-26.

[4] Hines, S. J. (2019). The Effectiveness of a Color-Coded, Onset-Rime Decoding Interventionwith First-Grade Students at Serious Risk for Reading Disabilities. Learning Disabilities Research \& Practice, 24(1), 21-32.

[5] Kenny, A., \& Qiang, Z. (2003). Information and communication technologies and broad-based development.In ICT \& development: Enabling the information society. Washington, D.C: The World Bank Group.

[6] Kinyanjui, M., Mwasa, M., \& Mbutu, P. (2014). Challenges facing effective implimentation of Free primary education in Public schools: A case study of Githunguri District Kiambu County. International; Journal of Scientific and Research Publication , 4(9) 225-3153.

[7] Mingaine, L. (2013). Challenges in the Implementation of ICT in Public Secondary Schools in Kenya. International J. Soc. Sci. \& Education, 4(1), 224-238.

[8] Nicanor, D. (2015). ICT processes in Namibia: Reflections of 2015. Namibia Education Journal, $12-$ 23.

[9] Omwancha, K. M. (2012). The implementation of an educational re-entry policy for girls after teenage pregnancy: A case study of public secondary schools in the Kuria District, Kenya. Nairobi: Victoria University of Wellington.

[10] Riesen, T., McDonnell, J., Johnson, J., Polychronis, S., \& Jameson, M. (2003). A Comparison of Constant Time Delay and Simultaneous Prompting Within Embedded Instruction in General Education Classes with Students with Moderate to Severe Disabilities. Journal of Behavioral Education, 12(4), 241-259.

[11] Shifonono, H. (2013). ICT integration in the teaching of Biology. Journal of Educational Psychology, 2 478-487.

[12] Zimba, R., \& Beau, T. (2005). ICT in Higher education. Journal of Psychology, 12-17. 